Marchesini, R.; Cruz, R.A. Turismo de base comunitária em estuário e manguezal: uma alternativa para o pescador artesanal. Revista Brasileira de Ecoturismo, São Paulo, v.6, n.5, nov-2013/jan2014, pp.896-909.

\title{
Turismo de base comunitária em estuário e manguezal: uma alternativa para o pescador artesanal
}

\author{
Community-based tourism in estuary and mangrove: an alternative to \\ the artisanal fisherman
}

\section{Renato Marchesini, Renata Antunes da Cruz}

\section{RESUMO}

No seminário sobre pesca artesanal da Baixada Santista, realizado Instituto de Pesca de Santos, em maio de 2003, deparamos com a dificuldade que os pescadores artesanais têm em se manter devido a sobrepesca, concorrência com grandes armadoras de pesca e período de defeso. Estes afetam não somente a economia da comunidade, como também sua autoestima, cultura e valores. As comunidades reconhecem a importância do defeso para a manutenção do pescado, porém a ajuda de custo (salário-desemprego) que recebem do governo, isto quando cadastrados, não é suficiente para suas necessidades. O turismo de base comunitária vem a ser uma opção de atividade para a comunidade pesqueira, permitindo-lhes trabalhar no ecossistema local e em seu próprio espaço, divulgando suas tradições, conhecimentos e tão rica cultura caiçara. A atividade segue como linha de raciocínio, a utilização da comunidade de pescadores artesanais, desenvolvendo o turismo de pesca e o turismo contemplativo, que é realizado por pessoas interessadas em conhecer e contemplar a cultura caiçara, a paisagem do manguezal e estuário e suas relações. Nestes nove anos foram realizados estudos, observações e pesquisas sobre fatores decisivos para a elaboração lógica deste trabalho. São eles: manguezal e estuário - a sua biologia e ações antrópicas, a pesca - categorias e tipos de pesca, o pesque e solte, tamanho mínimo, cota de captura, licença de pesca, defeso, seguro desemprego e critérios para benefício e a população tradicional caiçara - sua origem, cultura e relatos. Foi tomado como referência e estudo de caso os pescadores artesanais da Rua Japão e Parque Bitarú em São Vicente/SP. Na compilação desta pesquisa surgiu o Pescando Resultados, que propõe diretrizes para o fomento da atividade de turismo de base comunitária. A metodologia utilizada na elaboração do trabalho foi a pesquisa bibliográfica, documental e exploratória, com entrevistas não estruturadas com os pescadores artesanais. Este trabalho busca informações e objetiva soluções para elaboração de um programa de atividade turística de base comunitária para os pescadores artesanais atuarem na época de defeso. Esta atividade poderá fornecer subsídios para uma política de envolvimento sustentável.

PALAVRAS-CHAVE: Turismo de Base Comunitária; Defeso; Pescador Artesanal; Estuário; Manguezal.

Página 896 Revista Brasileira de Ecoturismo, São Paulo, v.6, n.5, nov 2013-jan 2014, pp.896-909.

Sociedade Brasileira de Ecoturismo. Rua Dona Ana, 138, Vila Mariana, São Paulo, SP - Brasil. E-mail: rbecotur@sbecotur.org.br; Tel. (55-II) 99I96-7685 


\section{ABSTRACT}

At seminar on artisanal fisheries of Santos, conducted by the Institute of Fisheries of Santos, in May 2003, we faced great difficulty that fishermen have to sustain themselves due to overfishing, competition with large shipowners and fishing closed season. These factors affect not only the community economy, but also their selfesteem, culture and values. Communities recognize the importance of closure for the maintenance of fish, but the allowance (unemployment benefits) they receive from the government, when enrolled, is not sufficient for their needs. The community-based tourism becomes an optional activity for the fishing community, allowing them to work in the local ecosystem and its own space, spreading their traditions, knowledge and rich caiçara culture. The activity follows as a logic line, the use of the fishermen community, developing fishing tourism and contemplative tourism, which is done by people interested in knowing and contemplating the Caiçara culture, the landscape of mangrove and estuary, and their relation. In these nine years there have been done some studies, observations and research on key factors for the logic preparation of this task. They are: mangrove and estuary - its biology and human actions, fishing categories and types of fishing, catch and release, minimum sizes, catch quotas, fishing license, closed season, and criteria for unemployment benefit, and caiçara traditional population - their origin, culture and stories. It was taken as reference and case study for the artisanal fishermen the places Rua Japão and Parque Bitarú in São Vicente / SP. In compiling this research came the Fishing Results, which proposes guidelines for enhancing the activity of community-based tourism. The methodology used in preparing the task was the bibliographical and exploratory research, with unstructured interviews with fishermen. This work seeks information and has the objective to find solutions to prepare a program of community-based tourism for the fishermen to work with at the time of closure. This activity will provide support for a policy of sustainable involvement.

KEYWORDS: Community-Based Tourism; Closed Season; Artisan Fisherman; Estuary; Mangrove.

\section{Pescando resultados}

Este artigo analisa o incentivo ao turismo de base comunitária, atividade que gera renda, conserva os recursos naturais e contribui para a manutenção da cultura local (caiçara).

De acordo com Aldo Leopold (1949 apud DIEGUES, 2000), uma decisão sobre o uso da terra é correta quando tende a preservar a integridade, a estabilidade e a beleza da comunidade biótica que inclui o solo, a água, a fauna e flora e também as pessoas.

O alvo de estudos foi a colônia de pescadores artesanais da Rua Japão e Parque Bitarú em São Vicente (SP), colônia de pescadores denominada Z4, devido à 
sua distribuição geográfica de comunidades pesqueiras. As informações obtidas baseiam-se em observações sistemáticas, levantamento de dados e conversas informais com as comunidades de pescadores.

A situação atual destes caiçaras é preocupante. O risco de extinção deste personagem brasileiro nato é eminente, devido à diminuição dos estoques pesqueiros pela sobrepesca, à poluição e ao desmatamento, assim como também à concorrência com grandes armadoras de pesca.

Em algumas épocas do ano o Instituto Brasileiro do Meio Ambiente (IBAMA) estabelece portarias de defeso para determinadas espécies de pescado, as quais são imprescindíveis para a manutenção dos estoques pesqueiros, reconhecidos pelo próprio pescador artesanal. No período de defeso o Governo Federal dispõe, a título de seguro-desemprego, um salário mínimo para os pescadores artesanais (quando cadastrados).

Hoje muitos deles abandonam seus costumes para lidar em outras ocupações dentro das cidades, como: construção civil, caseiros e outros, quando não são levados à marginalidade. Estes fatores refletem na perda do importante etno-conhecimento empírico do funcionamento do mundo natural em que vivem.

O turismo responsável e organizado pode ser uma alternativa para o resgate, conservação e manutenção da diversidade cultural e biológica destas colônias de pescadores.

Segundo o WWF-Brasil (2001, apud VITAE CIVILIS \& WWF-Brasil, 2003), 0 turismo deve respeitar os direitos, desejos, valores e experiências dos locais e prover a oportunidade para que amplos setores da comunidade contribuam nas decisões e nas consultas sobre o planejamento e administração do turismo. Devem ser consideradas tradições locais nas construções e o conhecimento e a experiência das comunidades locais em manejo sustentável dos recursos, buscando maximizar os benefícios para as comunidades, promovendo o recrutamento, treinamento e emprego de pessoas do lugar.

Trata-se do esforço da reorientação da experiência turística, trocando a massificação por uma vivência autêntica, mais próxima da realidade local (tanto da comunidade, quanto dos espaços, significados por seus usos tradicionais). Reside aí a essência do turismo comunitário, prática da visitação intencional à "alma" do lugar e das pessoas que o habitam (SANTOS, 2010, p.127).

Para o pescador artesanal não há nada mais fascinante do que o meio onde vive, e que pelas dificuldades de seu cotidiano, acaba se transformando em um herói anônimo. Um trabalho, sem dúvida, próprio para pessoas de muita fibra e coragem.

Está certo o educador Paulo Freire (1997), quando diz que a leitura do mundo precede a leitura da palavra. E a leitura do mundo resulta de experiências concretamente vividas por um indivíduo. 
Em matéria de Roteiros Náuticos (embarcados) em regiões "desconhecidas", a contratação e presença de um guia/piloteiro local se apresenta como uma necessidade irrefutável. Isto porque, a partir do conhecimento vivido e acumulado, é ele o profissional capaz de ler os segredos e os mistérios das regiões como mangues, estuários e outros lugares de rica biodiversidade e de berço marinho, com imenso potencial ecoturístico, como: passeios náuticos, estudo do meio ou pescarias. Sendo assim o pescador artesanal é o personagem dos mais próprios, como também capacitados para a atividade de turismo neste ambiente.

A navegabilidade em mangues e estuários torna-se mais segura quando feita por pilotos experientes e atentos. Bancos de areias estão sempre se deslocando devido o fluxo das marés, troncos flutuantes à deriva e muitas árvores e tocos ainda não apodrecidos exigem do guia/piloteiro certa destreza, além de deixar o visitante sempre mais à vontade para poder curtir a pescaria e contemplar a natureza, tornando o roteiro mais seguro e agradável.

O piloteiro ou pirangueiro, recebe atualmente a conotação mais ampla de guia de pesca. Seu desempenho interfere diretamente no resultado da experiência das viagens. Até porque, entre outras habilidades, ele sabe conduzir os passageiros através dos meandros e dos labirintos das águas, escolhendo os melhores percursos. É capaz de perceber alterações climáticas, marés, correntes marítimas (cuidando assim da segurança do barco e dos passageiros), podendo este também descrever a rica biodiversidade local. No caso de pescarias, apontar, com certo grau de certeza, as estruturas mais produtivas para a isca mais adequada. É claro que é preciso definir o tipo de pescaria desejada, se de fundo, se com iscas artificiais ou outras.

O pescador artesanal geralmente carrega consigo um imenso repertório de histórias. Ouvir os relatos e ter a chance de conhecer narrativas autênticas, nascidas de aventuras reais, é uma oportunidade "ímpar". Certa vez, durante uma das pescarias que acompanhamos durante a elaboração deste estudo, percebemos que $o$ piloteiro fazia uma imensa curva quando navegava no estuário. Perguntamos a razão dessa manobra e ele nos respondeu: "Sabe, o demônio encheu de pedras pontiagudas a margem direita deste canal. Para fugir do demônio é que eu fiz essa curva tão grande" (piloteiro Pepe, fato ocorrido em 16/06/2004, no canal de São Vicente, durante acompanhamento de pescaria realizada pelos pescadores artesanais do Parque Bitarú).

No chamado "check list" de planejamento em um roteiro náutico, o item "piloteiro" deve ter prioridade absoluta - isso porque, sem ele, sempre existirá a possibilidade de não fisgarmos absolutamente nada, por desconhecimento de onde, como e o que pescar, ou então, este também pode evitar que sua diversão se torne um transtorno, pois estão aptos a navegar com segurança na região.

O conceito de pesque e solte inclui-se nesta proposta como conduta consciente, sendo claro que o pescador amador poderá sim levar consigo algum exemplar de pescado desde que se respeite o período de defeso e o tamanho mínimo. Quando o pescador amador retornar do passeio, caso queira, poderá 
fornecer o pescado para as mulheres da comunidade, que podem tanto limpar, como prepará-lo de acordo com seus costumes (culinária caiçara), para sua degustação. São formas de agregar valores ao produto final.

\section{Propostas para fomento de atividade}

\section{Análise de mercado}

Embora a dinâmica do mercado recomende modestos investimentos, feitos de forma gradativa, na medida da aceitação e da receptividade do produto, a falta de recursos financeiros é um dificultador para expansão do projeto, que deve então manter sua estrutura pequena e enxuta.

Uma vez que o turismo náutico é visto ainda, de modo geral, como lazer, trabalhar com empresas e profissionais altamente responsáveis e envolvidos com a causa ambiental e cultural é fator estratégico para a conquista segura do mercado.

Segundo Vaz (1999), o posicionamento consiste em identificar um nicho de mercado (existente ou latente), e ocupá-lo, conquistando e mantendo a posição estratégica.

O fator cultural, no sentido amplo do termo, apresenta-se, assim, como o ponto de partida para a criação da imagem mercadológica, mas que acabaria depois se estendendo a todos os setores.

A cidade de São Vicente (SP) recebe anualmente grande fluxo de turistas, tendo como maior fator de estímulo o turismo "sol e praia", sendo assim possível também deslocá-los para outras atividades de lazer que a cidade oferece, bem como as atividades com a população caiçara.

\section{Apoio dos setores}

É preciso demonstrar a importância do fomento da atividade e buscar apoio junto ao poder público e à iniciativa privada, os quais também se beneficiarão.

Deve-se expandir alianças e parcerias com operadores e agências de turismo e lojas especializadas de pesca, estimulando a inclusão da região em seus roteiros, tornando-a atrativa como fonte de rentabilidade para suas operações, através do estabelecimento das condições comerciais vantajosas para ambos os lados. É de fundamental importância a realização de fam tours (viagens de familiarização) para mostrar aos parceiros e à imprensa os recursos turísticos e equipamentos da região.

A realização de fam tours junto a estes setores pode demonstrar que a atividade proposta é viável para a manutenção e resgate da cultura caiçara, gerando renda aos envolvidos e desenvolvendo o turismo de base comunitária. 


\section{Marketing}

"Marketing Turístico é um conjunto de atividades que facilitam a realização de trocas entre os diversos agentes que atuam, direta ou indiretamente, no mercado de produtos turísticos" (VAZ, 1999, p.18)

A estratégia de marketing deve seguir alguns princípios:

- Marketing responsável: passar todas as informações necessárias e reais do produto, inclusive os aspectos negativos, como período de chuvas e período de mosquitos;

- Marketing direcionado: escolher operadoras, agências e parceiros que tenham filosofia em comum.

- Manter um produto de alta qualidade.

- Preço competitivo com destinos quando semelhantes.

- Conquistar mais lugar na mente do turista e dos profissionais de turismo este é um trabalho constante de relações públicas e implica usar bem canais de multiplicação, como guias de turismo, agente de viagens, turismólogos, biólogos, ambientalistas, imprensa e boca-a-boca, que dão credibilidade aos produtos e ajudam para reforçar esta "marca" cultural e atrair viajantes independentes.

- Participação em eventos regionais e outros para aumentar a base de empresas agenciadoras.

- Conquista de clientes específicos: com base em banco de dados de contatos deve ser feito uma análise de clientes "preferenciais" que devem ser conquistados. Isto implica inicialmente numa mala direta dirigida para estes clientes alvos.

- Deve-se ser feito monitoramento do esforço promocional, medindo o custo/ benefício do investimento de tempo e dinheiro.

- Criação de website ou Blog - este sempre atualizado com mudanças de preços, pacote e estações.

O principal elemento do produto e projeto é a participação comunitária. O turista que tem como visão a consciência ecológica, tradicionalmente procura destinos que gerem benefícios para as comunidades locais, e não hesitam em pagar um pouco a mais por um produto cujos retornos sejam revertidos diretamente para a população local. A participação comunitária deve ser promovida e divulgada, já que é um elemento que proporciona uma diferenciação em relação a outros produtos oferecidos no mercado brasileiro.

O envolvimento sustentável tem dois componentes básicos. Primeiro, as 
ações voltadas para a transformação da realidade devem fortalecer o envolvimento das relações das sociedades com os ecossistemas locais. No caso de populações tradicionais, que merecem atenção diferenciada, devem ser respeitados os seus direitos à propriedade e ao manejo dos ecossistemas naturais. Devem ser valorizados e aprimorados os sistemas tradicionais de manejo dos recursos naturais, buscando uma maior sustentabilidade e produtividade (DIEGUES; VIANA, 2000).

Outro elemento é a possibilidade do desenvolvimento de pesquisas na área $\mathrm{e}$ a de acesso à informação sobre os ecossistemas. Já que o turismo de base comunitária tem um foco no aprendizado e na descoberta da natureza e das manifestações culturais locais. Estimular a realização pesquisas científicas na área que abrange o projeto é uma oportunidade para a divulgação, como exemplo: mídia impressa, documentários e outros instrumentos de divulgação que atingem até os mercados em outros países e incentivam um tipo de visitação que é compatível com os objetivos de conservação e desenvolvimento.

\section{Vendas}

A comercialização dos produtos é de responsabilidade da colônia de pescadores Z4 e agências de turismo receptivo local. De acordo com Vaz (1999), o produto turístico é um conjunto de benefícios que o consumidor busca em uma determinada localidade e que são usufruídos tendo como suporte estrutural um complexo de serviços oferecidos por diversas organizações.

O preço deve ser calculado com base de custos operacionais e fixos da operação e análise de mercado. A análise de custos deve ser feita através de planilha de custos.

Para o planejamento, deve-se lembrar que o produto a ser oferecido está ainda evoluindo. Um aumento de preço sempre deve ser respaldado em melhoria do produto ou por aumento de custo.

\section{Comissionamento agências e operadoras}

Para os clientes, fazer a reserva através de agência é vantajoso, pois a agência organiza todos os trechos da viagem, desde transportes, seguros, hospedagem e outros. Para a colônia de pescadores Z4 é também vantajoso trabalhar com agências, pois estas podem captar o cliente (nacional e internacional) e têm maior capacidade organizacional para efetuar campanhas de marketing periódicas.

As agências devem enviar o pagamento com antecedência (antes da chegada do turista). As agências devem fazer o depósito do valor NET do pacote, isto é, preço balcão menos a comissão. Não é vantajoso trabalhar com agências que não auxiliam no pagamento do cliente. Se o turista paga direto à colônia de pescadores, não é necessário o envolvimento da agência. 
Para bom entendimento fica destacado os termos de venda:

- Preço Balcão ou Rack Rate - termo cobrado para o cliente final (o turista);

- Preço Neto, Net ou Líquido - Valor que a colônia de pescadores recebe das agências (preço balcão menos a comissão da agência).

Cada agência ganha uma comissão em cima do preço balcão quando efetua uma venda. Esta comissão varia de 10 a 30\% dependendo de alguns fatores: quando a agência investe em marketing do produto, por exemplo, os produtos tem posição privilegiada no catálogo e site da agência? Qual é o mercado da agência? Por exemplo, é um mercado grande ou pequeno? Quantas pessoas a agência envia por ano? Se a agência envia uma média de 10 pessoas por ano, não está fazendo uma boa divulgação ativa do produto e só envia clientes espontâneos. Portanto a comissão deve ser menor.

Não é aconselhado trabalhar com agências que querem uma comissão muito alta em relação a seu poder de venda ou maior que 30\%. Estas agências não têm como objetivo ajudar o projeto e desenvolvimento da atividade, mas provavelmente pretendem usar a boa imagem do projeto para ter vantagens próprias.

Uma vez que as agências comecem a vender o produto é importante zelar pelo bom uso do projeto, as informações divulgadas e a cobrança de preços corretos.

\section{Oficinas de treinamento}

Deve-se propiciar capacitação profissional às pessoas da comunidade local envolvidas com as questões relacionadas a atividade, visando a melhoria na qualidade da prestação de serviços de atendimento aos turistas.

O programa de capacitação pode vir a identificar ofícios tradicionais, alguns até mesmo esquecidos, principalmente aqueles ligados ao extrativismo e ao artesanato, para acomodá-los dentro da gama de serviços ofertados ao visitante. A pesca por meios tradicionais, por exemplo, pode continuar tendo sua importância de subsistência, assim como oferecer ao visitante uma atividade singular, por acompanhar as técnicas de captura do peixe e depois degustá-lo (BORGES, 2003, p.295).

\section{Oficinas de sensibilidade para a comunidade}

Essas oficinas, destinadas a representantes de órgãos públicos, políticos, empresários, líderes comunitários e demais pessoas interessadas no desenvolvimento da atividade, devem despertar 0 interesse da comunidade para 0 envolvimento na atividade, incentivar órgãos públicos e empresários locais a trabalharem em prol de atividade, e apontar uma nova alternativa de emprego e renda 
para o desenvolvimento da comunidade.

Por desenvolvimento de comunidade entenda-se conferir poderes aos grupos locais para controlar e gerenciar reservas valiosas, por meio de mecanismos que não só a sustentem, mas que também satisfaçam as necessidades econômicas, sociais e culturais do grupo. (HORWICH, 2002, pg. 256).

De acordo com SWARBROOKE (2002), as comunidades são raramente homogêneas, ou têm um único ponto de vista sobre cada questão. Há uma necessidade de desenvolver mecanismos para arbitrar as visões conflitantes que surgirão sobre o turismo em qualquer comunidade.

Dentro os temas que deveriam ser abordados, podemos citar:

- Noções básicas sobre a pesca amadora como atividade de lazer e de conservação ambiental;

- A importância da pesca amadora como instrumento de desenvolvimento sócio-econômico e de conservação ambiental, com uma comparação de dados entre pesca amadora e comercial;

- Abordagem de dados e informações, principalmente sobre o fluxo turístico e receita gerada pela atividade de pesca amadora no mundo e no Brasil;

- Potencial brasileiro para o desenvolvimento da atividade em termos de recursos naturais, cultura voltada à pesca e disponibilidade de recursos humanos nas comunidades;

- Visão da comunidade para investimentos na pesca amadora mediante as oportunidades existentes na própria região.

- Sugestões o estímulo da organização local, a capacitação profissional e o planejamento como base para o desenvolvimento sustentável da atividade.

\section{Guias de pesca e passeios contemplativos}

O guia de pesca/piloteiro que exerce sua função com profissionalismo é um atrativo a mais para os turistas e pescadores esportivos. Sua capacitação visa melhorar a qualidade dos serviços prestados, de modo a incentivá-los a conservar os recursos ambientais, divulgar o uso de anzol sem farpa, iscas artificiais e a prática do pesque e solte. Também é preciso incentivar órgãos públicos e empresários a trabalharem em prol do turismo de pesca; envolver a população local na atividade; apresentar uma alternativa de emprego e renda para as comunidades locais.

Dentre os temas importantes para esse público-alvo, pose-se citar:

- Ecologia e Meio Ambiente - considerando que a pesca amadora é praticada em ambientes naturais, cuidados com o meio ambiente são requisitos básicos para a manutenção da atividade. Dessa forma, devem ser apresentadas noções sobre os impactos da atividade, cuidados com o lixo, 
fogo, mata ciliar, espécies nativas etc.;

- Marinharia - em uma atividade que envolve pessoas, os aspectos de segurança são de extrema importância para evitar acidentes de qualquer natureza. Além de conhecer a legislação, é necessário que o guia perceba e pratique todas as normas de segurança;

- Geografia - conhecimentos gerais sobre o mundo, o Brasil e, principalmente, a região onde vive, são questões importantes que visam o crescimento cultural do guia de pesca;

- Biologia - noções sobre a biologia dos peixes, seus hábitos reprodutivos, alimentação, comportamento e outras características. Quanto maior o conhecimento do guia sobre os recursos naturais que envolvem sua atividade, mais facilmente ele entenderá a necessidade de conservar esses recursos;

- Pesque e Solte - um dos fundamentos básicos para o desenvolvimento sustentável da pesca esportiva e, em alguns casos, de garantia da manutenção dos estoques pesqueiros. Entender a dimensão desse conceito e saber manusear o peixe para soltá-lo ainda com capacidade de sobrevivência, seria o objetivo principal desse tema;

- Iscas Artificiais - o desenvolvimento setorial e globalização de novas técnicas de pesca. Os turistas solicitarão cada vez mais essas informações; além disso, o estímulo ao uso de iscas artificiais é uma forma de reduzir a utilização de iscas naturais e contribuir para a manutenção dos estoques pesqueiros;

- Manutenção e Preparação de Equipamentos - saber escolher e montar corretamente um equipamento de pesca, dá maior segurança ao turista e garante um melhor resultado na pescaria (nós, anzóis sem farpa e amolados, empates, líderes etc.);

- Idioma Inglês - o Brasil tem atraído cada vez mais turistas estrangeiros que se encantam com os peixes e as belezas naturais do país. Não se tem a pretensão de que o guia de pesca/piloteiro fale inglês fluentemente inicialmente, mas sim que conheça algumas palavra básicas (bom dia, obrigado, por favor, deseja isso ou aquilo, sim, não, vara, linha, anzol, etc.), para, no mínimo, poder dar segurança ao turista e conseguir exercer sua função com eficiência. São palavras fáceis que permitem o entrosamento entre as partes;

- Relacionamento com o Turista - não basta ter informação e pescar bem, porque a atividade não é solitária. O turista também valoriza o bem-estar, simpatia, aparência, boa vontade, prazer pelo trabalho, higiene pessoal, etc. Esses aspectos também fortalecem o mercado; 
- Primeiros Socorros - como proceder corretamente nos acidentes comuns à atividade: ferroada e mordida de peixe, picadas de insetos, anzol no corpo do pescador, entre outros, bem como noções gerais em situações de maior gravidade;

- Mecânica - noções básicas de mecânica é um aspecto de segurança que pode evitar situações desagradáveis para o guia e o pescador;

- Legislação - o guia de pesca/piloteiro deve ter conhecimento das regras que regem a pesca esportiva em nível federal e estadual para problemas com a fiscalização e contribuir para a conservação dos recursos pesqueiros. Devem ser apresentados os principais pontos dos instrumentos legais que tratam da pesca amadora;

\section{Manipulação de alimentos}

O principal objetivo dessa oficina seria sensibilizar sobre a importância do responsável pelo estabelecimento na qualidade sanitária dos alimentos, e informar os princípios básicos da segurança alimentar e identificar os procedimentos que colocam em risco esses princípios.

Dentre os temas sugeridos, pode-se citar: contaminação dos alimentos; doenças transmissíveis por alimentos; microbiologia alimentar (microorganismos, binômio tempo/temperatura); procedimentos de higiene e desinfecção (equipamentos e utensílios, instalações, alimentos e pessoal); cuidados na aquisição, recebimento, armazenamento e transporte dos alimentos etc.

\section{Período de defeso \& pegue e solte}

Como já ressaltada a importância destes conceitos, é improcedente acreditar que a atividade possa ser sustentável sem o devido respeito a esses princípios. Portanto, a consciência e a capacitação do pescador torna-se fator chave para a atividade.

\section{Licença de pesca amadora e seus conflitos}

O licenciamento é a forma que os governos federal e estadual dispõem para controlar a exploração dos recursos pesqueiros e arrecadar recursos para implementação de planos de gerenciamento e fiscalização do meio ambiente, de forma a garantir a manutenção dos estoques pesqueiros.

Salvo os menores de idade, aposentados e pescadores que somente usam vara com linha simples (sem molinete ou carretilha) ou linha de mão, todos os que não se enquadram nestes dispositivos tem por dever possuir a licença para poder desenvolver a atividade de pesca amadora, que por ser muito pouco divulgada acarreta hoje em várias apreensões de equipamentos de pesca feitos pelo próprio 
IBAMA e pela polícia ambiental.

No Estado de São Paulo não existe nenhum órgão que emita a licença em nível estadual, restando a qualquer pescador amador que queira pescar legalmente no Estado, requerer a licença de âmbito federal cedida pelo IBAMA e válida por 1 ano. Esta licença necessária para a atividade é classificada como categoria "B" Embarcada.

Supondo que o turista não é um exímio pescador, somente pesque eventualmente ou até nunca antes pescou, o valor cobrado para essa licença ( $R \$$ 60,00 na época deste estudo) dificulta a operacionalização do produto, tornando a atividade elitista. Como solução seria a hora de pleitear a criação de um órgão estadual, pois nos Estados em que existe este órgão regulamentador os valores da licença são mais acessíveis; ou também junto ao IBAMA a possibilidade de criação por exemplo, de uma licença por um mês, com valores mais reduzidos.

Esta proposta daria a oportunidade de maior controle dos recursos naturais, a possibilidade de se fomentar e gerar renda, tanto diretos para comunidades tradicionais como indiretos para diversos setores da economia.

\section{Classificação de embarcações}

As embarcações utilizadas pelos pescadores artesanais são classificadas como de "pesca". É necessária para a atividade de turismo uma dupla classificação, pois a intenção é que o pescador artesanal continue sua atividade de pesca, porém possa também desenvolver o turismo.

A classificação de embarcações pode e é realizada pela Capitania dos Portos (Marinha), e somente ela pode autorizar a dupla classificação. A embarcação vai ter que ser adaptada para o turismo, como se estabelece nas NORMANS (Normas da Autoridade Marítima), com material de salvatagem e outros.

\section{Plataforma de pesca e turismo}

Outra proposta deste trabalho é assegurar que o local (Rua Japão - São Vicente/SP) onde habitam diversos pescadores artesanais, seja referência no setor de roteiros náuticos turísticos bem como local de desembarque e venda de pescados. $\mathrm{O}$, o local poderá proporcionar maior conforto e segurança tanto para os pescadores artesanais como para os visitantes, e poderá ter o nome de "Plataforma Caiçara".

A plataforma será dividida em duas partes:

A - Destinar-se-á à atividade de roteiros náuticos, será o ponto de 
embarque e desembarque de turistas.

B - Destinar-se-á a atividade pesqueira realizada pelos pescadores artesanais, onde seu pescado será desembarcado, como também ser ofertado para venda, para o comércio em geral e direto para a população.

\section{Conclusão}

Para ser efetivo, qualquer programa de proteção, conservação ou de gestão de ecossistemas costeiros deveria ser preventivo (proativo) ao invés de ser corretivo (reativo); reduzindo a necessidade da adoção de medidas corretivas e ou punitivas. Deveriam visar o futuro e não o presente, contabilizando as experiências do passado, para permitir a efetiva integração entre conservação ambiental, cultural e envolvimento sócio-econômico justo e eqüitativo.

Qualquer atividade de turismo com base comunitária somente pode ser sustentada numa política que permita a participação efetiva de todos os atores locais, especialmente os "comunitários", e seja respeitosa aos seus etnoconhecimentos e etnociências.

Devido as atuais dificuldades existentes na comunidade de pescadores artesanais de São Vicente, é sugerida uma implantação gradual desta proposta buscando primeiramente a consciência de que os frutos serão a consequência da persistência e o esforço gerado, assim sendo a longo prazo.

Desse modo, a elaboração e viabilização do projeto depende de tantos fatores externos que se torna quase impraticável estabelecer objetivos rígidos. Todo o planejamento deve manter certa flexibilidade, adequando-se às oportunidades que vão surgindo.

A proposta está sendo trabalhada com os próprios pescadores artesanais (colônia Z-4), a Prefeitura Municipal de São Vicente e as empresas interessadas da iniciativa privada (agências de turismo, lojas de equipamentos de pesca e outras), aos quais também caberão a implantação da proposta.

É sugerida também uma revisão da licença de pesca amadora (IBAMA), pois a mesma demonstra ser uma dificuldade na implantação do turismo de pesca. Uma proposta de licença de menor tempo de vigência e preço mais acessível deve ser estudada.

Concordamos com Thoreau (1986), quando afirma que "Não importa que os primeiros passos pareçam pequenos: o que se faz bem feito se faz para sempre. Mas preferimos debater o assunto: essa é a nossa missão".

\section{Referências bibliográficas}

BORGES, M.M. Capacitação Comunitária. In: MITRAUD, S. (org), Manual de Ecoturismo de Base Comunitária: ferramenta para um planejamento responsável. Brasília: WWF Brasil, 2003. 
DIEGUES, A.C.; VIANA, M. Comunidades Tradicionais e Manejo dos Recursos Naturais da Mata Atlântica. São Paulo: NUPAUB Provográfica, 2000. FREIRE, P.A Pedagogia da Autonomia. São Paulo: Ed. Paz e Terra, 1997. $\mathrm{HORWICH}$, R.H. et al. O ecoturismo e o desenvolvimento da comunidade: a experiência de Belize. In: LINDBERG, K.; HAWKINS, D.E. (orgs), Ecoturismo: um guia para planejamento e gestão. 4⿳亠丷a Ed. São Paulo: Ed. SENAC, 2002.

SANTOS, A.F.L. Construir, Habitar, Viajar: Reflexões acerca da relação comunicaçãoturismo comunitário. In: PANOSSO NETTO, A.; GAETA, C. (orgs). Turismo de Experiência. São Paulo: Ed. SENAC, 2010.

SWARBROOKE, J. Turismo Sustentável: Conceitos e Impacto Ambiental. $3^{\underline{a}} \mathrm{Ed}$. São Paulo: Ed. Aleph, 2002.

THOREAU, H.D. A Desobediência Civil e outros escritos. Rio de Janeiro: Ed. Rocco, 1986.

VAZ, G.N. Marketing Turístico Receptivo e Emissivo. São Paulo: Ed. Pioneira, 1999.

VITAE CIVILIS; WWF-Brasil. Sociedade e Ecoturismo: na trilha do desenvolvimento sustentável. São Paulo: Ed. Peirópolis, 2003.

Renato Marchesini: Caiçara Expedições, São Vicente, SP, Brasil.

Email: renato@caicaraexpedicoes.com

Link para o currículo Lattes: http://lattes.cnpq.br/0376503646329356

Renata Antunes da Cruz: Caiçara Expedições, São Vicente, SP, Brasil.

Email: biologarenata@yahoo.com.br

Data de submissão: 21 de junho de 2012

Data de recebimento de correções: 19 de junho de 2013

Data do aceite: 04 de julho de 2013

Avaliado anonimamente 